\title{
First Report of Phoma multirostrata in Egypt
}

\section{A.A.El-Wakil and Amal.A.Khalil}

Seed Pathology Research Dept. ,Plant Pathology Research Institute, A.R.C.

Dark grey lesions were observed on Cantaloupe stems grown at El-Bostan ( Behiera Governorate). A species of phoma was consistently isolated from diseased stems. The pathogen was identified as Phoma multirostrata according to its morphological characteristics, DNA sequencing comparisons and pathogenicity testing. Symptoms progressed from necrotic stem lesions $(1-2 \mathrm{~mm})$ to extensive necrosis of stems and leaves (Fig. 1). Disease incidence was 10\%. A fungus was consistently isolated on PDA medium. Fungal colonies on PDA produced greenish-gray mycelium that became black after 10 to 16 days incubation at $25^{\circ} \mathrm{C}$ with $12 \mathrm{~h}$ photoperiod.

Pathogenicity tests were performed by spraying a spore suspension $\left(1 \times 10^{5} \mathrm{cfu} / \mathrm{ml}\right)$ prepared from 25 -day-old culture onto the plants. Stem necrosis was observed. The fungus was re-isolated from the lesions of the inoculated plants and verified morphologically. The pycnidia of the fungus Phoma multirostrata are black, embedded in the infected stem tissues and developed on senescence lesions. Pycnidia contain single celled masses of spores. The rDNA internal transcribed spacer (ITS) region was amplified using primers ITS 1/ ITS4 and PCR product sequenced. Blast analysis of the 515bp amplicon showed $100 \%$ homology with a sequence of $P$. multirostrata (GenBank Accession No. MK 3360917).

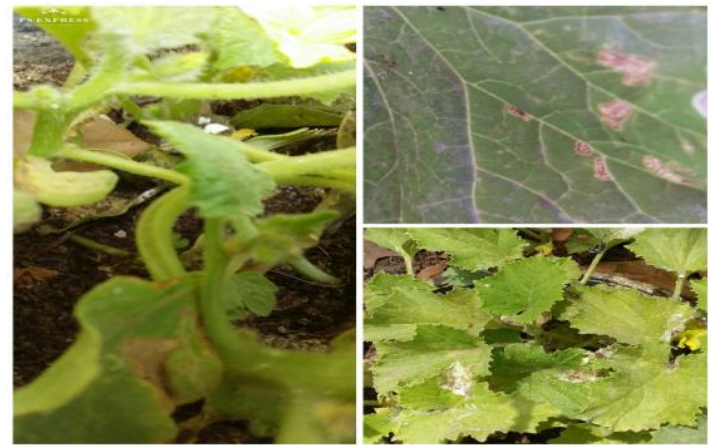

Fig. 1. Leaf spot on cantaloupe leaves

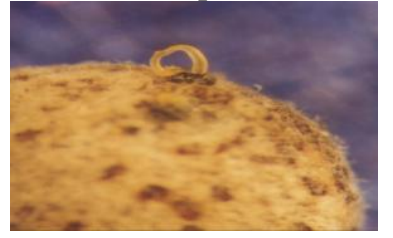

Fig. 2. Conidia released from pycnidia on cantaloupe fruit 


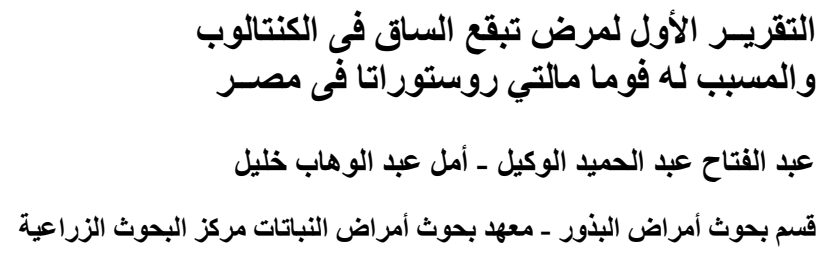

لوحظت تبقعات رمادية على سوق الكنتالوب فى منطقة البستان بالنوبارية

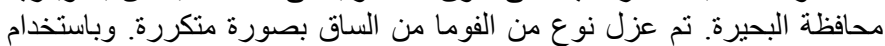

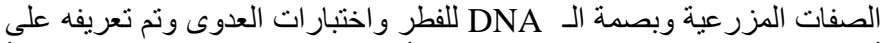

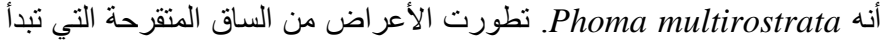

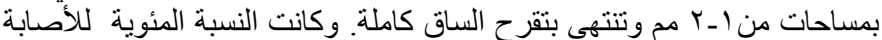

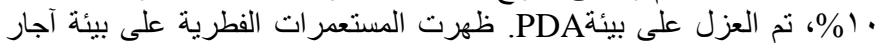

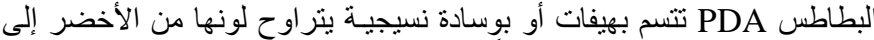

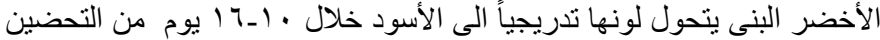

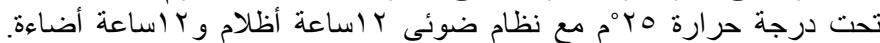

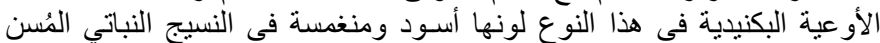

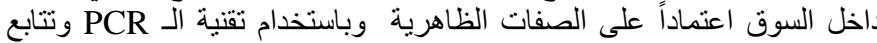

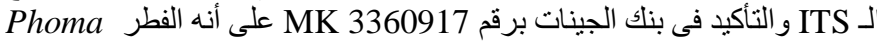
multirostrata P.N.Mathur, S.K.Menon\&Thirum.) 